\title{
PSEUDOMUTISMO ACINETICO ("LOCKED-IN" SYNDROME) EM DOENÇA DE CHAGAS ACIDENTAL
}

\author{
GUILBERTO MINGUETTI* \\ JOS* FARIA RATTON **
}

Pseudomutismo acinético ("locked-in" syndrome) foi inicialmente descrito por Plum e Posner em $1966^{\circ}$ e desde então muitos casos têm sido relatados. Os autores relatam o caso de paciente jovem com doença de Chagas provavelmente adquirida através de transfusão de sangue, que desenvolveu quadro súbito de pseudomutismo acinético.

\section{OBSERVACXO}

R.F., 26 anos, masculino, arquiteto, atendido em seu domicílio por cardiologista; seus pais relatavam que o paciente apresentara queda súbita ao solo mantendo inicialmente os membros superior e inferior do lado direito em hiperextensão. Embora mantivesse os olhos abertos, não respondia às perguntas a ele dirigidas. Aos primeiros contatos, o facultativo considerou a necessidade de internamento imediato sob os cuidados de neurologista. Ao dar entrada no hospital, seus pais relataram que o paciente estava perfeitamente bem até segundos antes da queda e não acrescentavam qualquer outro dado de história que pudesse interessar ao caso, a não ser o fato de ter o paciente apresentado, três anos antes, quadro de hematêmese consequente a úlcera gástrica perfurada. O fato ocorreu quando o paciente e sua familia passavam pela cidade de Ourinhos, Estado de São Paulo. Dada a gravidade do sangramento, o paciente foi levado a hospital local e recebeu duas unidades de sangue fresco. Além desse detalhe, a familia negava qualquer outra possibilidade que pudesse ser considerada importante sob o ponto de vista epidemiológico quanto a doença de Chagas. Ao exame, verificaram-se alteraçóes do ritmo cardíaco com presença de extrassistoles frequentes. $O$ paciente mantinha-se com os olhos abertos, porém impossibilitado de realizar qualquer movimento voluntário a não ser fechar e abrir as pálpebras e movimentar os olhos conjugadamente no sentido vertical. Através de código estabelecido entre o paciente e os examinadores observava-se que ele se mantinha orientado no espaço e quantu à própria pessoa. Os reflexos profundos, inicialmente hipoativos e simétricos, tornaram-se hiperativos nas primeiras 24 horas. Os reflexos plantares apresentavam-se em extensão desde o início do quadro.

Eletrocardlograma realizado no momento do exame mostrava extrasistolia ventricular e alterações da morfologia das ondas P e T. A tomografia computorizada cerebral mostrou grande infarto na porção ventral inferior da ponte (Fig. 1). Os exames laborato-

Trabalho das Disciplinas de Neurologia e Neurocirurgia da Universidade Federal do Paraná: * Professor Adjunto do Departamento de Clínica Médica (Neurologia); ** Professor Adjunto do Departamento de Clínica Cirúrgica (Neurocirurgia). 
riais incluindo-se glicemia, hemograma, colesterol, triglicérides, VHS, mucoproteínas, foram todos normais. Sorologia para lues, negativa. Reação de Guerreiro-Machado positiva por duas vezes, em dois laboratórios diferentes. Foram prescritos cuidados gerais, fisioterapia, digitálicos, anti-arrítmicos e anticoagulantes. O paciente evoluiu satisfatoriamente quanto ao estado geral. Neurologicamente, em alguns dias houve recuperação de pequenos movimentos dos membros superiores e inferiores que com dois ou três meses de evolução o paciente já movimentava com desenvoltura, deambulando com auxílio. Seis meses após o início do quadro, o paciente faleceu por parada cardíaca súbita.
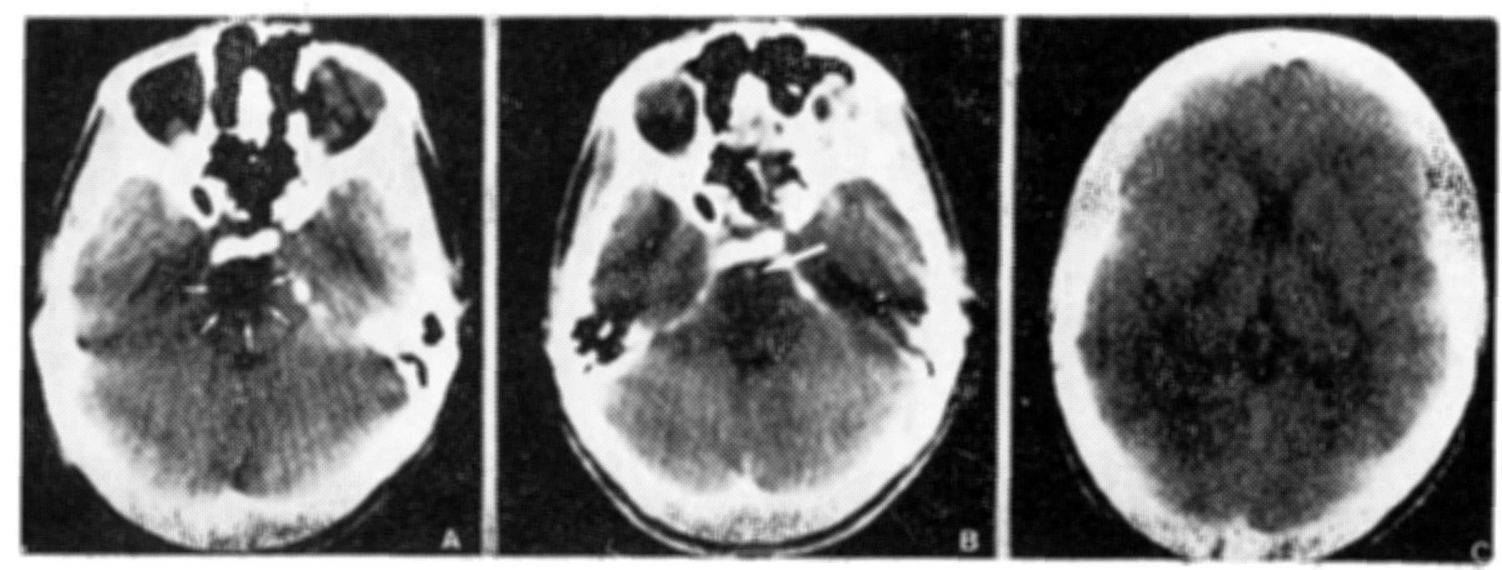

Fig. 1 - Em A, as setas indicam drea de baixos valores de atenuaçao (12-15H) nas porções ventrais da ponte. Após injeção endovenosa do contraste (B), os limites da lesão tornam-se menos nitidos, pois ocorre discreto acuimulo do mesmo na área lesada fazendo com que seus valores de atenuagão se aproximem dos valores de atenuaça do parênquima pontino situado ao redor da lesão. A seta indíca a artéria basilar. Em $C$ é apresentado corte tomografico wo nivel cerebral. Os ventriculos apresentam-se com forma, tamanho e posiç̃o normatis. Não são observadas alteracōes patologicas dos valores de atenuaça do tecido cerebral.

\section{COMENTARIOS}

A ocorrência do estado de vigilia acompanhada por mutismo e tetraplegia de origem pontina é chamado de pseudomutismo acinético, síndrome de de-eferenciação ou síndrome do cativeiro (locked-in syndrome). A síndrome é usualmente resultante de lesão na porção ventral das porções inferiores da ponte. Pressupõe-se que lesão aguda àquele nível destrói a base da protuberância e mantém intactas as grandes vias do sistema retículado que passam pela calota do tronco cerebral (tegmentum) e os mecanismos dos movimentos conjugados verticais dos globos oculares. Por isso mesmo, do ponto de vista anatômico, a síndrome é reconhecida como pontino-ventral. Graças à preservação da integridade do sistema reticulado ativador ascendente, o paciente permanece consciente (há preservação da vigilia e do conteúdo da consciência), mas é incapaz de comunicar-se devido a paralisia de todas as vias motoras eferentes (a afonia é devida a interrupção corticobulbar). Isto permite que o paciente se comunique com o mundo exterior apenas com os movimentos verticais dos olhos e com os movimentos palpebrais. Esta condição pode dar a impressão falsa de coma ou de mutismo acinético: no pseudomutismo acinético, o paciente 
dá mostras de estar consciente de si mesmo e do meio que o rodeia, enquanto que no mutismo acinético existe pouca ou nenhuma percepção consciente 5 . Alterações vasculares da fossa posterior são freqüentes nos casos de pseudomutismo acinético, sendo em geral decorrentes de doenças ateroscleróticas ou hipertensivas em pacientes com idade superior aos cinquienta anos.

A síndrome pseudomutismo acinético é por si só rara e chama a atenção o presente caso pela idade do paciente (26 anos) e pela natureza da patologia básica (doença de Chagas). Embora seja esta uma doença embólica por natureza, o comprometimento da circulação cerebral posterior é bem menos freqüente que o da anterior. Excetuando-se o mecanismo usual de transmissão por intermédio de triatomíneo, a transfusão constitui-se num fator de alto risco para a disseminação de doença. A transfusão de sangue permite a perpetuação da doença mesmo em áreas urbanas não endêmicas. Os primeiros casos de transmissão da doença através da transfusão de sangue foram relatados em 1952 por Freitas e col.8. A partir daí, inúmeros outros casos foram relatados pela literatura latino-americana. Entre tais publicações encontram-se as de Amato Neto e col.1,2, Becker ${ }^{4}$, Camargo e Leser ${ }^{6}$, Baldy e col. ${ }^{3}$.

No caso descrito, a falta de outros dados epidemiológicos nos leva a crer na possibilidade de infecção acidental, ou seja, via transfusão de sangue, pois a região de Ourinhos é área endêmica. A gravidade do caso chama a atenção para a necessidade de controle rigoroso dos doadores de sangue e que em situações de urgência nas quais haja necessidade de sangue fresco deva-se recorrer sempre a doadores conhecidos e controlados. Nas indicações de transfusão programada, deve-se exigir que o sangue a ser utilizado tenha sido submetido a testes sorológicos rigorosamente padronizados, embora estes possam ocasionalmente ser negativos mesmo quando se utilizam técnicas adequadas ? Do ponto de vista do diagnóstico anatômico da síndrome, a tomografia computorizada parece ser método promissor para a localização das lesões ao nivel da ponte. No caso específico da ponte, somente com a introdução de aparelhos com matrizes finas (256x256 ou mais) é que lesões àquele nível puderam ser avaliadas. Os primeiros aparelhos dispunham de matrizes de $80 \times 80$ e com tais matrizes a resolução é pouco satisfatória e a imagem obtida mostra os pequenos detalhes anatômicos de forma grosseira, dificultando o diagnóstico de lesões isquêmicas da ponte. Com o advento de aparelhos com matrizes superiores, a resolução foi muito melhorada e, com ela, a capacidade diagnóstica dos aparelhos, o que nos permite hoje observar com segurança as lesões pontino-ventrais que possam produzir o pseudomutismo acinético.

\section{RESUMO}

É relatado caso de adulto jovem do sexo masculino portador de doença de Chagas, provavelmente contraída de forma acidental (via transfusão de sangue), que desenvolveu quadro de pseudomutismo acinético. São considerados os aspectos anatômicos e funcionais da síndrome e as implicações de transfusão de sangue como fator de importância na transmissão da doença de Chagas. 


\section{SUMMARY}

\section{Locked-in syndrome by accidentaly transmited Chagas' disease.}

Chagas' disease is a major problem in Central and South America ${ }^{10}$. The disease is caused by Trypanosoma cruzi, a protozoon which may inhabit the blood and tissues of both man and animals. Although it may produce marked enlargement of several hollow viscera, myocardial involvement is the hallmark of chronic Chagas' disease. The clinical picture of chronic Chagas myocardites is one of insidious, progressive, prolonged congestive heart failure and cardiac enlargement. The almost invariable arrhythmias make syncope and sudden death common in patients both with or without congestive heart failure. Electrocardiographic abnormalities occur in 87 percent of patients with chronic Chagas disease and are often the initial manifestation of illnes. Pathological findings include mural trombosis which often results in pulmonary and central nervous system embolization. Trypanosoma cruzi is in general transmitted to human beings by the bite of haematophagus insects of the reduviidae family, but in the last years reports pointing out the importance of blood transfusions as infectious sources of Trypanosoma cruzi are becoming more and more frequent.

The authors present a case of a male young architect whitch contrated Chagas' disease probably by a blood transfusion and latter developed "locked-in" syndrome. It is discussed the importance of blood transfusion as a source of transmission of the disease even in non-endemic areas and the need to controlling all blood transfusions in countries where Chagas' disease is endemic. The authors also point out the importance of computed tomography in the diagnosis of lesions in the pons.

\section{REFERENCIAS}

1. AMATO NETO, V.; DOLES, J.; RASSI, A.; BORGES, A. P.; REZENDE, J. M. \& GOMES, M. C. O. - Relato de novos casos de transmissão da doença de Chagas por transfusão de sangue. Rev. Inst. Med. trop. São Paulo 10:46, 1968.

2. AMATO NETO, V.; MAGaLDI, C. \& BIANCHI, A. - Comprovação de mais um caso de transmissão da doença de Chagas por transfusão de sangue. Hospital (Rio) 64:123, 1963.

3. BALDY, J. L. S.; ; TAKAOKA, L.; CHIEFFI, P. P.; MOCELIN, A. J. \& BRANDINA, L. - Doença de Chagas por transfusão de sangue em Londrina, Parané. Relato de dois casos agudos tratados com nifurtimox. Rev. Inst. Med. trop. São Paulo 21:155, 1979.

4. BECKER, P. F. L. - Moléstia de Chagas aguda acidental por transfusão de sangue de doador chagásico. Rev. Inst. Med. trop. São Paulo 17:187, 1975.

5. CAIRNS, H.; OLDFIELD, R. C.; PENNYBACKER, J. B. \& WHITTERIDGE, D. Akinetic mutism with an epidermoid cyst of the 3rd ventricle. Brain 64:273, 1941.

6. CAMARGO, M. E. \& LESER, P. G. - Diagnóstico acidental de laboratório de infeções chagásicas agudas pós-transfusionais não suspeitadas. Rev. Ass. med. brasil. 20:335, 1974.

7. CAMPOS, C.; REZENDE, J. M. \& RASSI, A. - Prevalência da doença de Chagas no banco de sangue do Hospital das Clínicas de Goiania. Possibilidade de falha da reação de Guerreiro-Machado na seleção de doadores. Rev. Soc. brasil. Med. trop. 9:165, 1975. 
8. FREITAS, J. L. P.; ;BIANCALANA, A.; AMATO NETO, V.; NUSSENZWEIG, V.; SONNTAG, R. \& BARRETO, J. G. - Primeiras verificacões de transmissão acidental da moléstia de Chagas ao homem por transfusão de sangue. Rev. paul. Med. 40:36, 1952.

9. PLUM, F. \& POSNER, J. B. - The Diagnosis of Stupor and Coma. F. A. Davis Co., Philadelphia, 1966.

10. WHO TECHNICAL REPORT - Chagas' disease - Report of a study group. Tech. Rep. Ser. Wld. Hlth. Org. 202:1, 1960.

Hospital de Clinicas da U.Fr.Pr. (130 andar) - Rua General Carweiro, 1980 80.000, Curitiba, PR - Brasil. 